\title{
Sigmoid adenocarcinoma with metastases to the kidney: Report of a rare case and review of the literature
}

\author{
AUDRIUS DULSKAS $^{1}$, PAULIUS BAGURSKAS ${ }^{1}$, \\ ZALVYRAS SINKEVICIUS $^{1}$ and NARIMANTAS E. SAMALAVICIUS ${ }^{1,2}$ \\ ${ }^{1}$ Department of Abdominal and General Surgery, National Cancer Institute; ${ }^{2}$ Centre of Oncosurgery, \\ National Cancer Institute, Clinic of Internal Diseases, Family Medicine and Oncology, \\ Faculty of Medicine, Vilnius University, Vilnius LT-08406, Lithuania
}

Received September 17, 2014; Accepted May 7, 2015

DOI: $10.3892 / 01.2015 .3290$

\begin{abstract}
Distant metastases from colorectal cancer (CRC) most frequently spread to the liver and lungs. CRC metastasis to the kidney is extremely rare and may be generally associated with an unfavorable prognosis. Thus, patients with metastatic CRC and kidney metastasis are a diagnostic and therapeutic challenge. The present study reported the case of a 42-year-old male with a local recurrence of CRC following sigmoid resection with partial mesorectal excision, which had infiltrated the urinary bladder, requiring partial resection of the urinary bladder wall. After 4 years, the patient developed a recurrent tumor localized in the upper pole of the left kidney and underwent left nephrectomy. The patient remained disease-free 6 months after the surgery.
\end{abstract}

\section{Introduction}

Worldwide, $\sim 1.25$ million patients are diagnosed with colorectal cancer (CRC) and >600,000 CRC-associated mortalities are reported each year (1). The likelihood of colorectal cancer diagnosis increases in patients that are $>40$ years old; and increases progressively from the age of 40 years, rising sharply in patients $>50$ years old. Most $(>90 \%)$ cases of colorectal cancer occur in people aged 50 years or older (2). At least $50 \%$ of patients develop metastases, and the majority of these patients have unresectable tumors (3). CRC survival is highly dependent upon the stage of disease at diagnosis, and typically ranges from a 90\% 5-year survival rate for cancers detected at the localized stage; to a $70 \%$ rate for regional types; to a $10 \%$ survival rate for those diagnosed with distant metastatic cancer (4) In patients with recurrences, the most frequent sites

Correspondence to: Mr. Audrius Dulskas, Department of Abdominal and General Surgery, National Cancer Institute, Vilnius University, 1 Santariskiu Street, Vilnius LT-08406, Lithuania E-mail: audrius.dulskas@gmail.com

Key words: colorectal cancer, metastasis to the kidney, recurrence, chemotherapy are the liver, lungs, local and/or regional retroperitoneal, and peripheral lymph nodes. However, metastases of colorectal cancer in the kidney are considered to be extremely rare (5).

In the present study, the case of a 42-year-old male patient with metastatic sigmoid colon cancer with progression to the left kidney was reported. In addition, a review of the literature was performed.

\section{Case report}

The study was approved by the ethics committee of the National Cancer Institute (Vilnuis, Lithuania) and written informed consent was obtained from the patient prior to publication of the data. A 42-year-old male patient was admitted to the National Cancer Institute in December 2009 with left lower quadrant abdominal pain, obstipation, bloating and weight loss. Following double-contrast X-ray of the large intestine, a sigmoid tumor completely obstructing the bowel was diagnosed. The patient underwent sigmoid resection and partial mesorectal excision of 10x8 cm in size. Sigmoid colorectal carcinoma pT3NOM0 (stage 2) (6) penetrating the urinary bladder wall and upper rectum was identified. Subsequently, the patient received 6 cycles of adjuvant chemotherapy with fluorouracil and folinic acid (Mayo Clinic regimen) (7). The treatment did not produce any side-effects. The patient remained without any signs of disease relapse during followup, until February 2013, when he complained of blood in the urine. A pelvic magnetic resonance imaging scan was performed, which resulted in the diagnosis of a bladder tumor (a 4x5-cm mass was identified). However, chest and abdominal computed tomography (CT) scans did not reveal any distant metastases. The patient underwent transurethral resection of the bladder tumor and 8 cycles of adjuvant chemotherapy with capecitabine $\left(1,250 \mathrm{mg} / \mathrm{m}^{2}\right)$ twice daily, since he refused administration of intravenous chemotherapy. Histological analysis of the resected tissue demonstrated metastasis of the mucinous adenocarcinoma in the urinary bladder wall. In October 2013, surveillance imaging with a CT scan revealed the presence of an 81x66-mm tumor in the upper pole of the left kidney (Fig. 1). At admission, the physical examination demonstrated no abnormalities and the laboratory tests were unremarkable, while the carcinoembryonic antigen (CEA) 


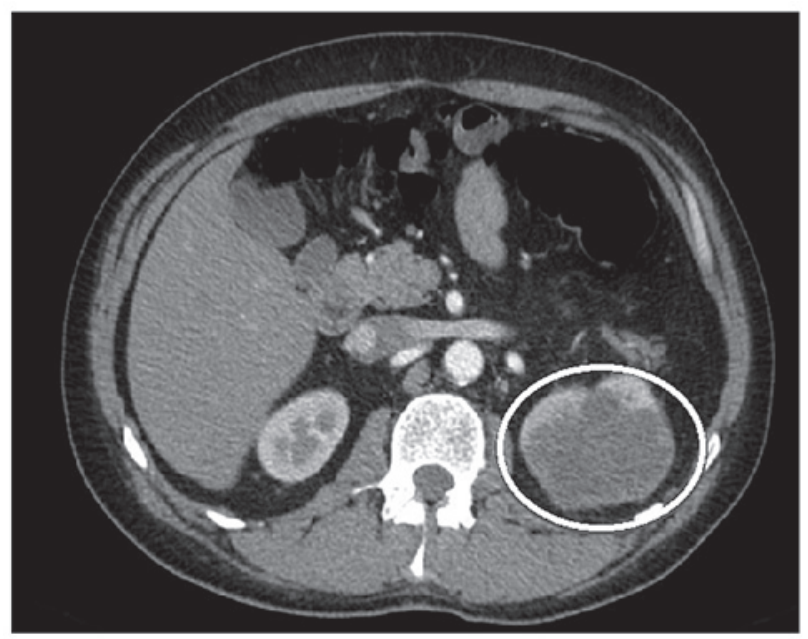

Figure 1. Abdominal computed tomography scan revealing a mass in the upper pole of the left kidney.

level was normal. Renal cellular carcinoma was suspected and the patient underwent biopsy of the kidney. Histological examination of the kidney biopsy tissue established a diagnosis of adenocarcinoma, representing a sigmoid cancer metastasis. During a laparotomy, left nephrectomy was performed. The nephrectomy sample revealed tumor infiltration of the perirenal and hilar fat of the renal capsule, with venous spread. Histologically, a metastasis from the primary large-bowel adenocarcinoma was diagnosed with KRAS gene mutation. The patient refused adjuvant chemotherapy. The patient was alive and remained disease-free 18 months subsequent to the surgery.

\section{Discussion}

Isolated metastatic involvement of the kidney is rare and sporadic, and usually occurs with concomitant carcinomatosis (5). In the majority of cases, solitary kidney metastases of $\mathrm{CRC}$ are asymptomatic and detected on surveillance imaging or as a result of increased CEA levels. Bracken et al performed an autopsy study of 11,328 patients and identified kidney metastases in only $2.7 \%$ of patients with CRC; however, the incidence of solitary metastases has not been previously reported (8). The present study utilized a computerized literature search using MEDLINE, PubMed and the Cochrane library and identified 14 cases of CRC metastasis to the kidney (5,9-21). The current case is the 15th. In the current patient, mucinous adenocarcinoma was diagnosed, which occurs in $\sim 10 \%$ of all cases of CRC (22). Pericolic and perirectal dissemination and metastasis are more common than other types of metastasis, and these tumors are more aggressive and atypical at presentation (5).

The current patient initially underwent surgery due to sigmoid cancer penetrating to the urinary bladder and upper rectum. However, the patient later developed a metastasis in the wall of the urinary bladder, and resection of the urinary bladder was then performed. In October 2013, a metastasis to left kidney was diagnosed on a CT scan. Therefore, retrograde spread of cancer cells possibly occurred intraluminally from the urinary bladder to the kidney in the present case, although no neoplastic infiltration was observed in the ureter. Previous studies have also proposed this type of dissemination (12). CRC is known to metastasize locally or distantly via the lymphatic and venous systems. In colon carcinoma, the lymphatic flow follows the major arteries. Tumors located between more than one major vessel may metastasize in any direction; however, the liver is by far the most commonly-involved organ. The colon is drained by the portal venous system, and thus metastases to the brain, spleen and kidney occur by arterial dissemination (5). Arterial dissemination is rare in colon cancer, with only $3 \%$ of all colon cancer metastases caused by arterial dissemination (9). Another study stated that perirenal tissues (Gerota's fascia and peritoneum) are very important in direct tumor dissemination and the restoration of a normal anatomical situation is essential (13).

The patient of the present study was asymptomatic for 4 years after the procedure. Kidney metastasis was only identified on a CT, without CEA level elevation. A biopsy was performed to rule out a second primary renocellular cancer. Systemic chemotherapy is the treatment of choice for CRC renal metastases and, with the exception of rare emergencies or cases with resectable disease, nephrectomy is not commonly used in the management of CRC renal metastases $(14,23)$. Other relative indications for surgery are tumors with perirenal hematoma and risk of rupture, as well as symptomatic patients (9). Another treatment option for symptomatic patients is percutaneous kidney resection (16).

In conclusion, isolated renal metastases of CRC without any other visceral metastases have rarely been reported in the worldwide literature. The present study reported one such rare case of $\mathrm{CRC}$ metastasis to the kidney.

\section{References}

1. Ferlay J, Soerjomataram I, Ervik M, Dikshit R, Eser S, Mathers C, Rebelo M, Parkin DM, Forman D and Bray F: GLOBOCAN 2012: Estimated Cancer Incidence and Mortality Worldwide: IARC CancerBase No. 11. Volume 1.0. IARC, Lyon, France, 2012.

2. National Cancer Institute: SEER Cancer Statistics Review, 1975-2005. http://seer.cancer.gov/archive/csr/1975_2005/results_ merged/sect_06_colon_rectum.pdf. Accessed May 10, 2015.

3. Grothey A, Van Cutsem E, Sobrero A, et al: Regorafenib monotherapy for previously treated metastatic colorectal cancer (CORRECT): an international, multicentre, randomised, placebo-controlled, phase 3 trial. Lancet 381: 303-312, 2013.

4. Jemal A, Clegg LX, Ward E, Ries LA, Wu X, Jamison PM, Wingo PA, Howe HI, Anderson RN and Edwards BK: Annual report to the nation on the status of cancer, 1975-2001, with a special feature regarding survival. Cancer 101: 3-27, 2004.

5. Aksu G, Fayda M, Sakar B and Kapran Y: Colon cancer with isolated metastasis to the kidney at the time of initial diagnosis. Int J Gastrointest Cancer 34: 73-77, 2003.

6. Greene FL, Page DL, Fleming ID, Fritz AG, Balch CM, Haller DG and Morrow M (eds): Colon and rectum. In: AJCC Cancer Staging Manual. 6th edition. Springer-Verlag, New York, NY, USA.

7. Tomiak A, Vincent M, Kocha W, Taylor M, Winquist E, Keith B, Sawyer M, Griffeth S, Whiston F and Stitt L: Standard dose (Mayo regimen) 5-fluorouracil and low dose folinic acid: prohibitive toxicity? Am J Clin Oncol 23: 94-98, 2000.

8. Bracken RB, Chica G, Johnson DE and Luna M: Secondary renal neoplasms: An autopsy study. South Med J 72: 806-807, 1979.

9. Klaasse Zn, Prabhakar R, Madi R, Shingleton WB and Terris MK: Bilateral metachronous colon cancer metastasis to kidneys: a rare case with a treatment dilemma. Uro Today Int J 6: $1-5,2012$ 
10. Wolff JM, Boeckmann W and Jakse G: Spontaneous kidney rupture due to a metastatic renal tumour. Case report. Scand J Uro Nephrol 28: 415-417, 1994

11. Waleczek H, Wente MN and Kozianka J: Complex pattern of colon cancer recurrence including a kidney metastasis: A case report World J Gastroenterol 11: 5571-5572, 2005.

12. Kibar Y, Deveci S, Sümer F and Seçkin B: Renal papillae metastasis of sigmoid colon adenocarcinoma. Int J Urol 12: 93-95, 2005.

13. Nelson J, Rinard K, Haynes A, Filleur S and Nelius T: Extraluminal colonic carcinoma invading into kidney: A case report and review of the literature. ISRN Urol 2011: 707154, 2011.

14. Dagnoni C, Granero LCS and Rovere RK: Sigmoid adenocarcinoma with renal metastasis. Clin Pract 1: e88, 2011

15. Komeya M, Nakaigawa N, Sano F, Kagota M, Murakami T, Makiyama K, Miyoshi Y, Ogawa T, Uemura H, Yao M, et al: A case of upper urinary tract metastases from sigmoid colon cancer. Hinyokika Kiyo 55: 339-343, 2009 (In Japanese).

16. Milbank AJ, Savage SJ, Angermeier KW, Ng CS and Streem SB: Metastatic cancer to the renal pelvis: A novel approach to management. Urology 64: 807-809, 2004.

17. Brambilla E, Heck AA, Cao JG, Toniazzo GT and Petteffi L: Isolated renal metastasis after colon cancer. Can J Urol 14: 3649-3650, 2007.
18. Lowe LH, Zagoria RJ, Chen MY and Dyer RB: Intraluminal renal metastasis from colon cancer simulating a fungus ball. Urol Radiol 13: 226-227, 1992.

19. Shiraishi T, Hasegawa Y, Itoh $H$ and Nakakuki K: Implantation of colon cancer cells onto renal pelvic mucosa. A case report. APMIS 97: 181-184, 1989.

20. Ho L, Wassef H, Henderson R and Seto J: Renal metastasis from primary colon cancer on FDG PET-CT. Clin Nucl Med 34: 596-597, 2009

21. Julianov A, Stoyanov H and Karashmalakov A: Late renal metastasis from sigmoid adenocarcinoma. Lancet Oncol 5: 726, 2004.

22. Numata M, Shiozawa M, Watanabe T, Tamagawa $H$, Yamamoto N, Morinaga S, Watanabe K, Godai T, Oshima T, Fujii S, et al: The clinicopathological features of colorectal mucinous adenocarcinoma and a therapeutic strategy for the disease. World J Surg Oncol 10: 109, 2012.

23. Melichar B, Morávek P, Ferko A and Podhola M: Metastatic colorectal carcinoma and kidney tumors: A report of four cases. Tumori 96: 483-486, 2010. 